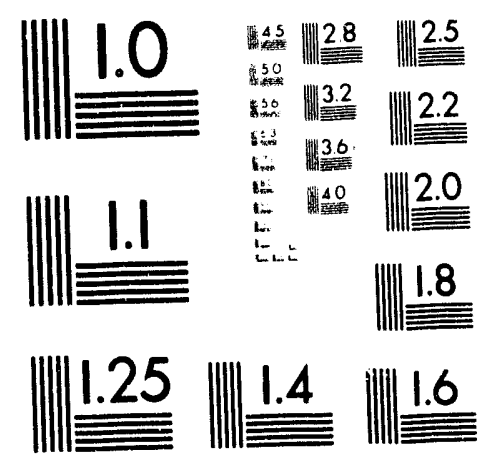



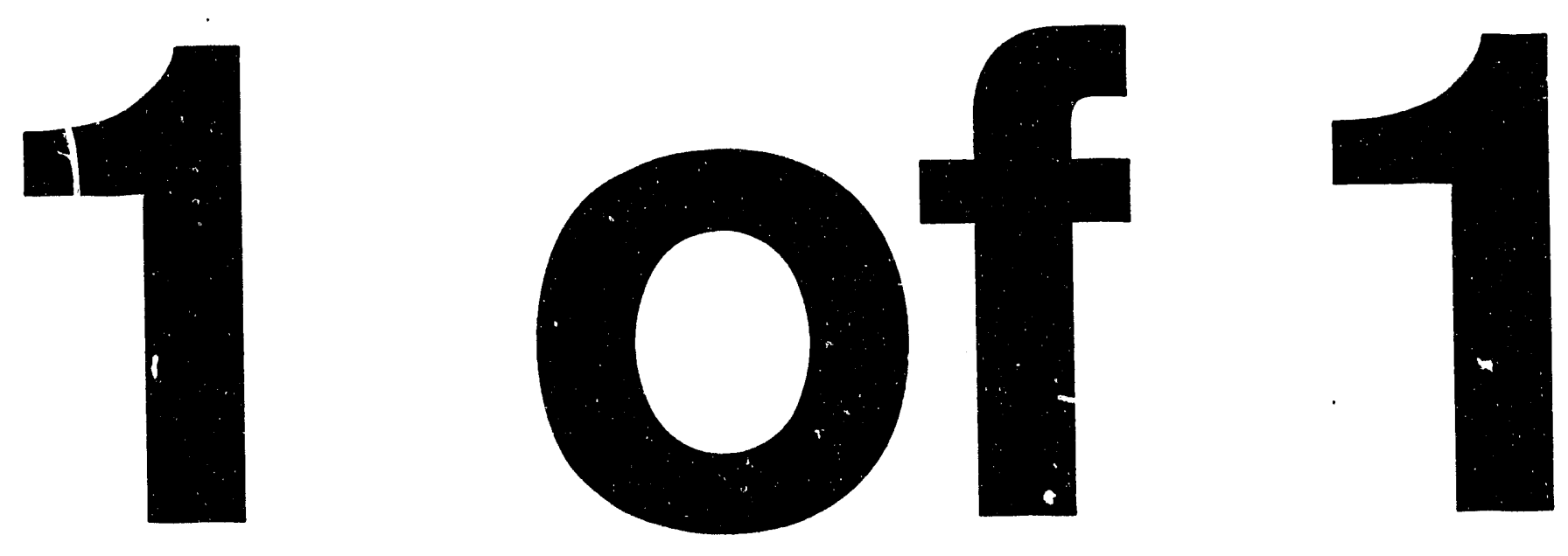
Velocity Measurements in a Boundary

Layer with a Density Gradient

\author{
P. Neuwald
}

H. Reichenbach

A.L. Kuhl

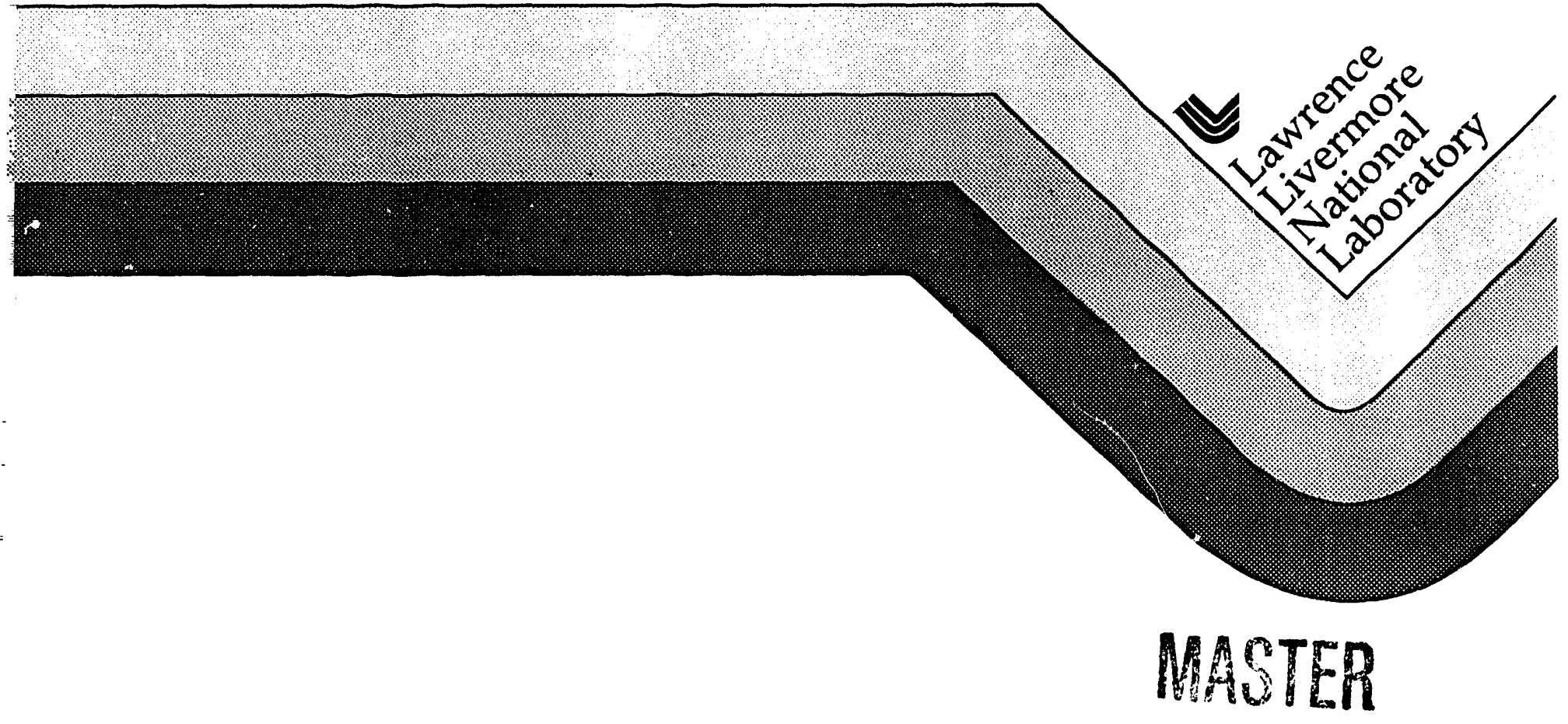




\section{DISCLAIMER}

Work performed under the auspices of the U.S. Department of Energy by Lawrence Livermore National laboratory under contract number W-7405-ENG-48.

This document war, prepared as an account of work spensored by an agency of the Inited States Grivernment. Neither the United States Government nor the University of California nor any of their employees, makes any warranty, express or implied, or assumes any legal liability or responsibility for the accuracy, completeness, or usefulness of any information, apparatus, product, or process disclosed, or represents that its use would not infringe privately owned rights. Reference herein to any specific commercial products, process, or service by trade name, trademark, manufacturer, or otherwise, does not necessarily constitute or imply its endorsement. recommendation, or favoring by the Inited States Government or the I/niversity of california. The views and opinions of authors expressed herein do not necessarily state or reflect those of the Linited States Government or the I niversity of California. and shall not be used for advertising or product endorseenent purposes. 


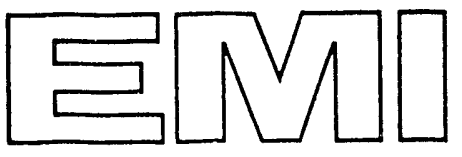

$\mathrm{T} 9 / 92$

Velocity Measurements in a Boundary Layer with a Density Gradient
P. Neuwald
H. Reichenbach
A. L. Kuhl 


\title{
Velocity Measurements in a Boundary Layer with a Density Gradient
}

\author{
P. Neuwald \\ H. Reichenbach \\ Ernst-Nach-Institut, Freiburg, FRG \\ A. L. Kuhl \\ Lawrence Livermore National Laboratory \\ El Segundo, CA
}

Norember 1992

Interim Report

Contract No DNA 001-91-C-0039

This work was sponsored by the Defense Nuclear Agency under RDT \& E RMSS Code B 4662 D RA RG 003524400 A AC 


\section{VELOCITY MEASUREMENTS IN A BOUNDARY LAYER WITH A DENSITY GRADIENT}

\section{SCOPE OF THIS REPORT}

Following the requirements of subtask 2.2 of the DNA contract, DNA 001-91-C0039, a number of experiments were performed at the EMI shock tube facility on shock waves propagating in a stratified atmosphere with density gradient modelled by air layered above Freon $\left(\mathrm{C} \mathrm{Cl}_{2} \mathrm{~F}_{2}\right)$. This report presents streamwise velocity data for the flow behind the shock front. Additional information from measurements of overpressure history and shadowgraphs of the flow will be presented in a future EMI-report (Ref. 2). 


\section{SECTION 1 \\ MEASUREMENT CONDITIONS}

\subsection{EXPERIMENTAL SETUP}

In order to generate the mixing layer of air and Freon, the test section of the EMI shock tube was equipped with the model shown in Figure 1. Freon is injected through four porous Filtrokelit elements that form the bottom wall of the channel.

The duration of the Freon injection and the diaphragm rupture were electronically timed to attain reproducible propagation conditions for the shock wave. Shado:" Schlieren pictures showed a good stratification and a good reproducibility ui the layer thickness. Figure 2 shows a preliminary estimate of the density ${ }^{1}$ profile.

The presented velocity data were measured with the LDV system described in a previous technical note (Ref. 3 ). Three data channels were recorded simultanously at each run. The probe volumes were located at half the channel width in $z$-direction and centered within the observation window in $\mathrm{x}$-direction. The $\mathrm{y}$-location (height above the channel bottom) was varied.

\subsection{SHock WaVE PaRaMeters}

The shock wave was generated by releasing a driver pressure of 5 bars into the shock tube at ambient pressure. The ambient temperature during the measurements varied from $27.3^{\circ} \mathrm{C}$ to $29^{\circ} \mathrm{C}$. The resulting shock wave has a Mach number $\mathrm{M}_{S}$ around 1.40 .

Recent tests with preshock interferog:ams showed that the Freon layer extends to the leading edge of the bottom wall $1020 \mathrm{~mm}$ from the center of the test section. Due to its smaller sound speed the shock wave is slowed down in the Freon layer, the $y$-dependance of the retardation leading to a curved shock front near the wall. The experimental findings show that a series of compression and expansion waves is set up by the reflection of the shock between the wall and the interface layer. In effect the shock is weakened; the front arrives at the measurement location at an average propagation speed 5 to $7.5 \%$ smaller than in pure air (that corresponds to a Mach number $\mathrm{M}_{S}$ around 1.3).

\footnotetext{
${ }^{1}$ The curve - a preliminary evaluation of an interferogram (see Ref. 2) - shows the local optical path length through the mixing layer
} 


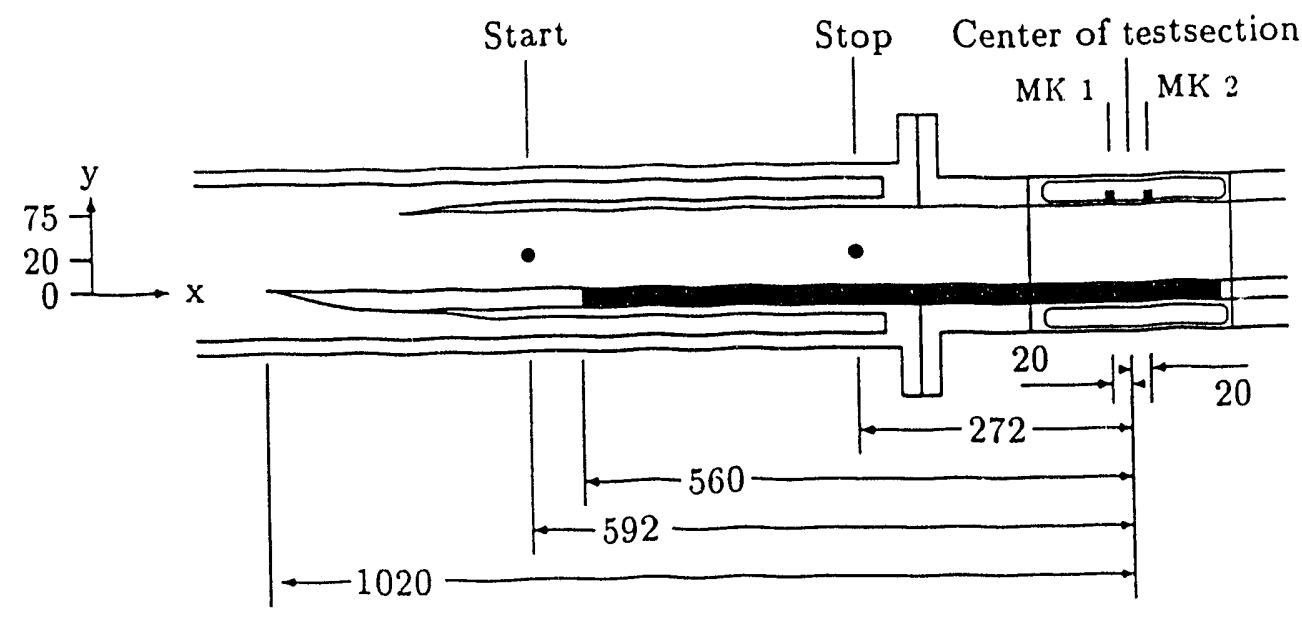

Figure 1: Schematic of the test section (lengths in $\mathrm{mm}$ )

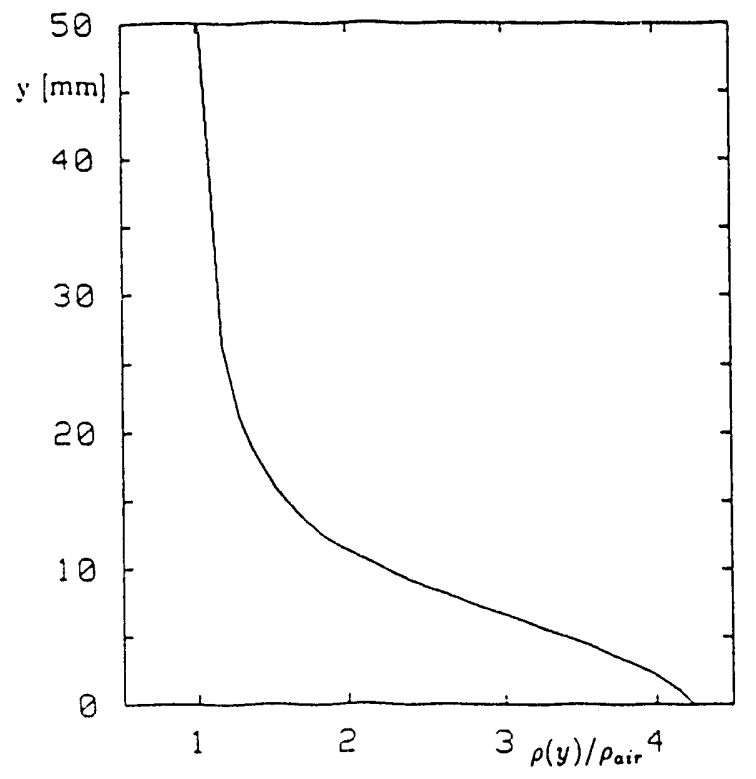

Figure 2: Density profile (qualitatively) 


\section{SECTION 2 \\ RESULTS OF THE VELOCITY MEASUREMENTS}

\subsection{OVERVIEIV}

An overview of the streamwise velocity distribution is given in Figure 3 . In the outer region of the flow (at $\mathrm{y}=45 \mathrm{~mm}$ and above), the main effect of the wave configuration is a finite rise time of the flow velocity. A comparable effect is found in the overpressure history measured at the upper channel wall ( see Figure 4 ).

At smaller values of $y$ three different time regimes exist in the flow behind the shock front. Directly behind the front it is dominated by a periodic disturbance due to the series of multifold reflections of the incident shock wave within the mixing layer. This disturbance decays with time, followed by a regime with only small velocity variations. Within these two regimes different runs show a good reproducibility. Approximately $1.5 \mathrm{msec}$ after tise shock front passage the smooth velocity histories tend to be interrupted by intervals of large variations. These random disturbances that are not reproducable might be specific to the shock tube geometry and Mach number.

In Figure 6 three different measurements in the height of $4 \mathrm{~mm}$ are shown as an example. For times greater than $1700 \mathrm{msec}$ the velocity histories differ significantly from each other. At smaller times the realisations agree very well in their essential characteristics. Minor variations can be found in the arrival time of the shock front and the period of the disturbance. These are mainly due to small variations of the layer thickness and other propagation conditions.

The period of the velocity fluctuations is found to be between 110 to $120 \mu \mathrm{sec}$. An analogue periodicity is found in pressure recordings. Furthermore a periodic spatial structure is found in Schlieren pictures of the flow (see Figure 5). The spatial period agrees well with the temporal period if one assumes that the structure passes the probe location with the shock wave velocity. The Schlieren photographs also reveal that the spatial period depends on the layer thickness. 

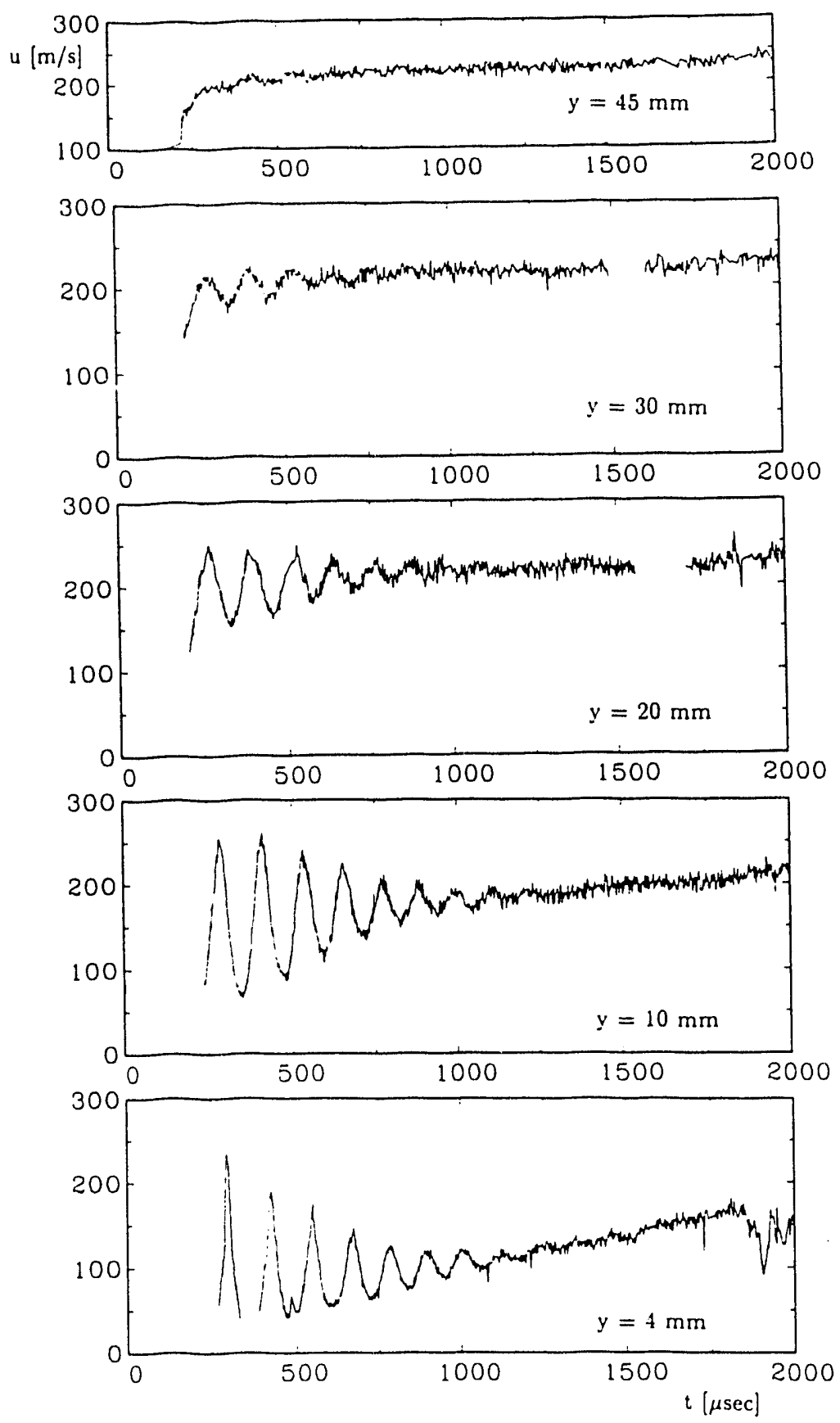

Figure 3: Streamwise velocity at different heights y 


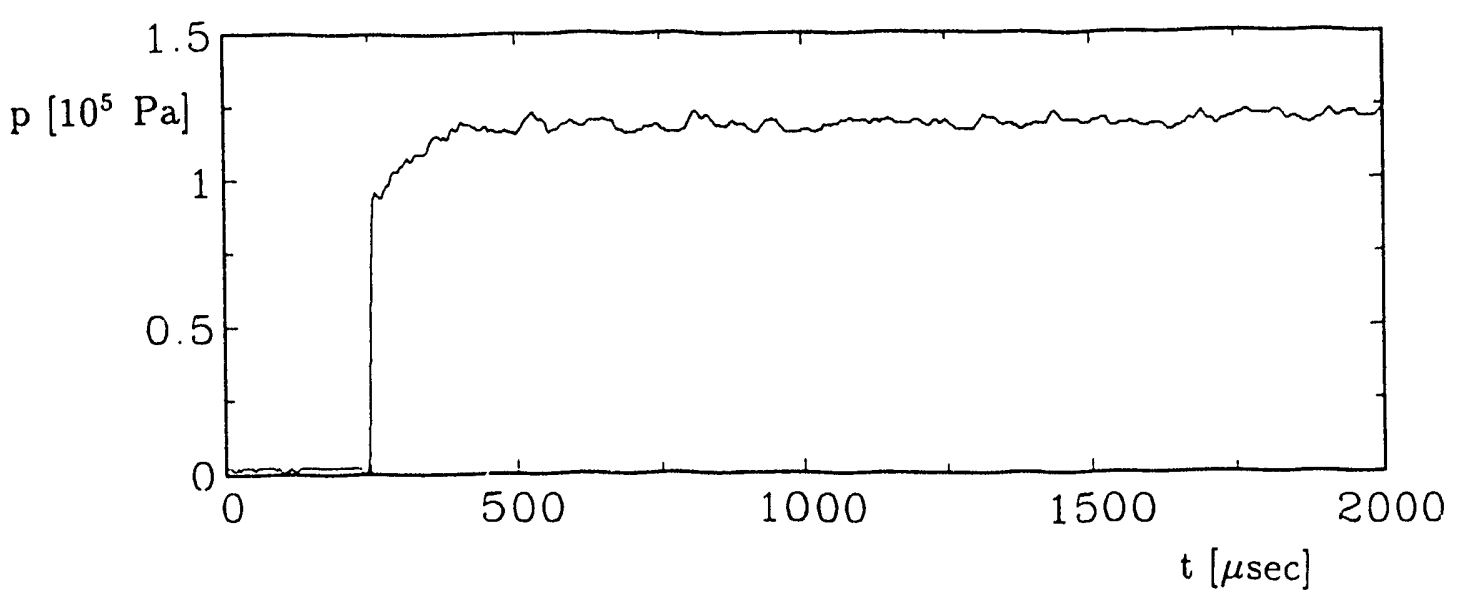

Figure 4: Pressure recording from gauge MK2 at the top wall

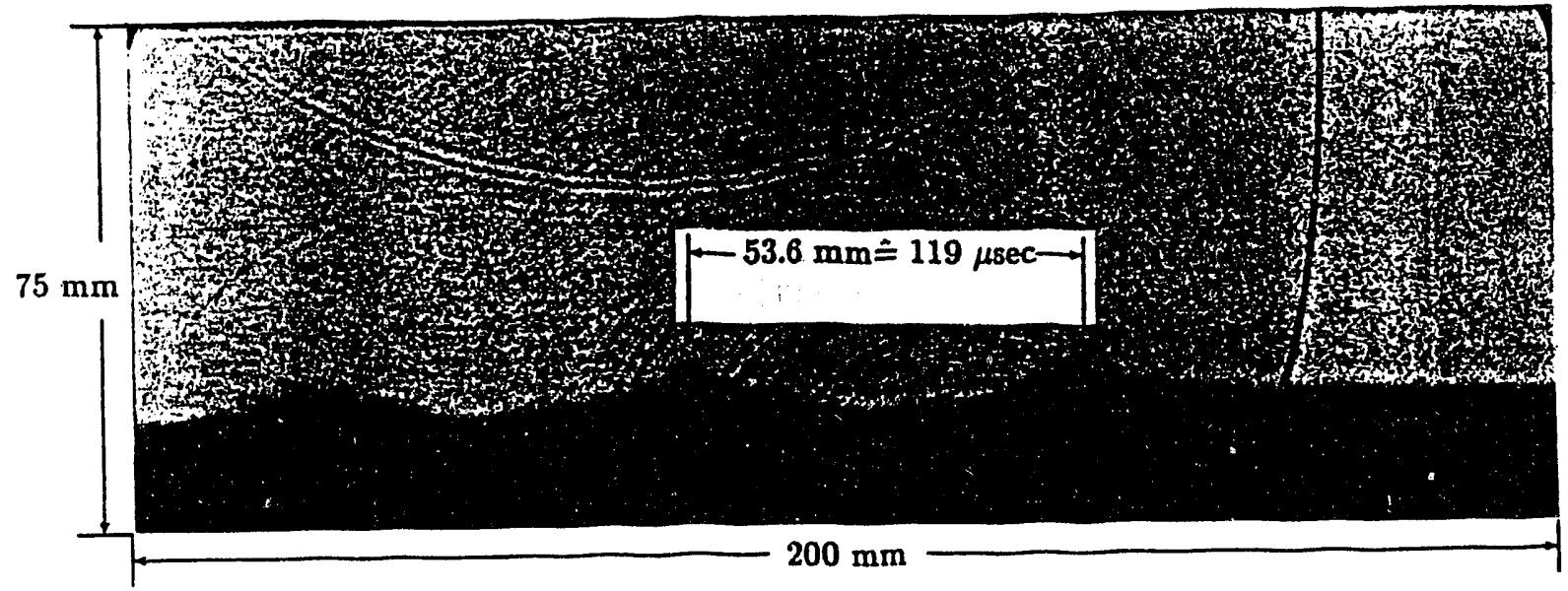

Figure 5: Schlieren-shadowgraph

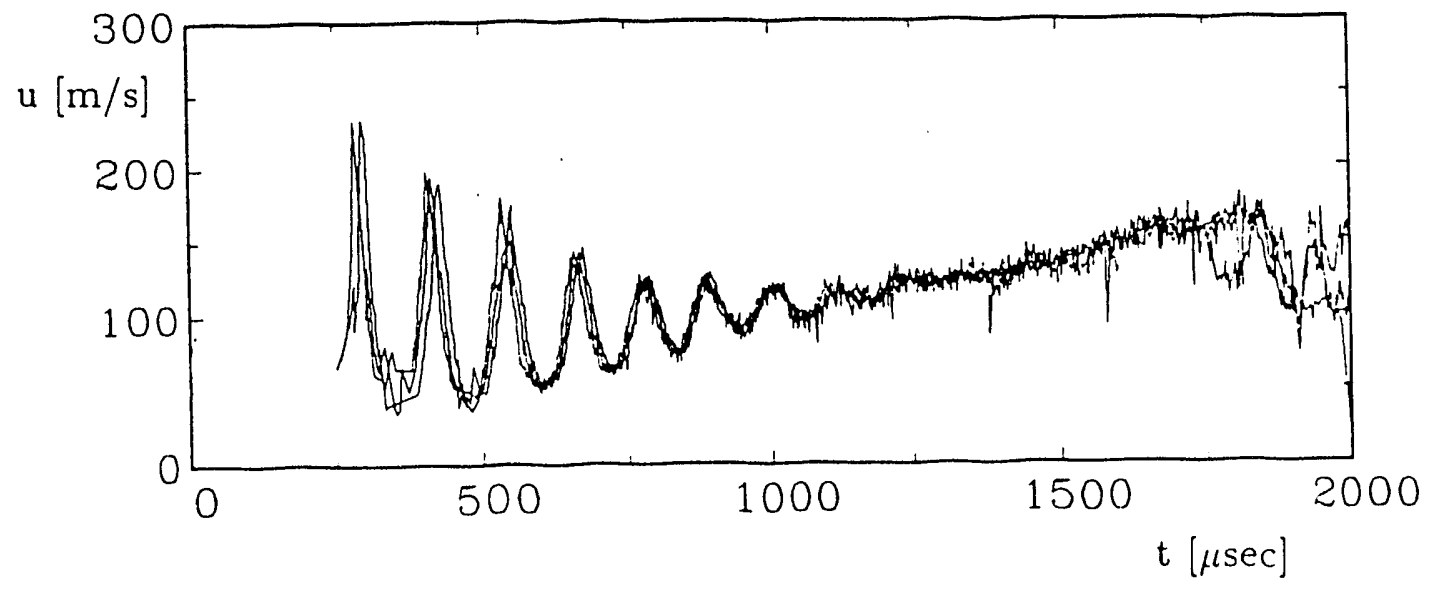

Figure 6: Different realisations of the velocity measurement at $y=4 \mathrm{~mm}$ 
The strength of the modulation of the velocity varies with the height as can be seen in Figure 7. The curve labeled "Mod 1" shows the velocity difference between the first velocity minimum and the second velocity maximum and the curve labeled "Mod 2" the difference between second maximum and second minimum. The largest modulation can be found for $y$-values between 6 and $10 \mathrm{~mm}$. For larger $y$-values the modulation decays approximately exponentially.

In contrast to its strength no significant systematic change with height can be found for the phase of the modulation.

The modulation is characterized by sharp peaks and broader minima, especially near to the wall. The temporal decay as well as the spatial decay in $y$-direction tend to smooth this characteristic out to a more sine-like modulation.
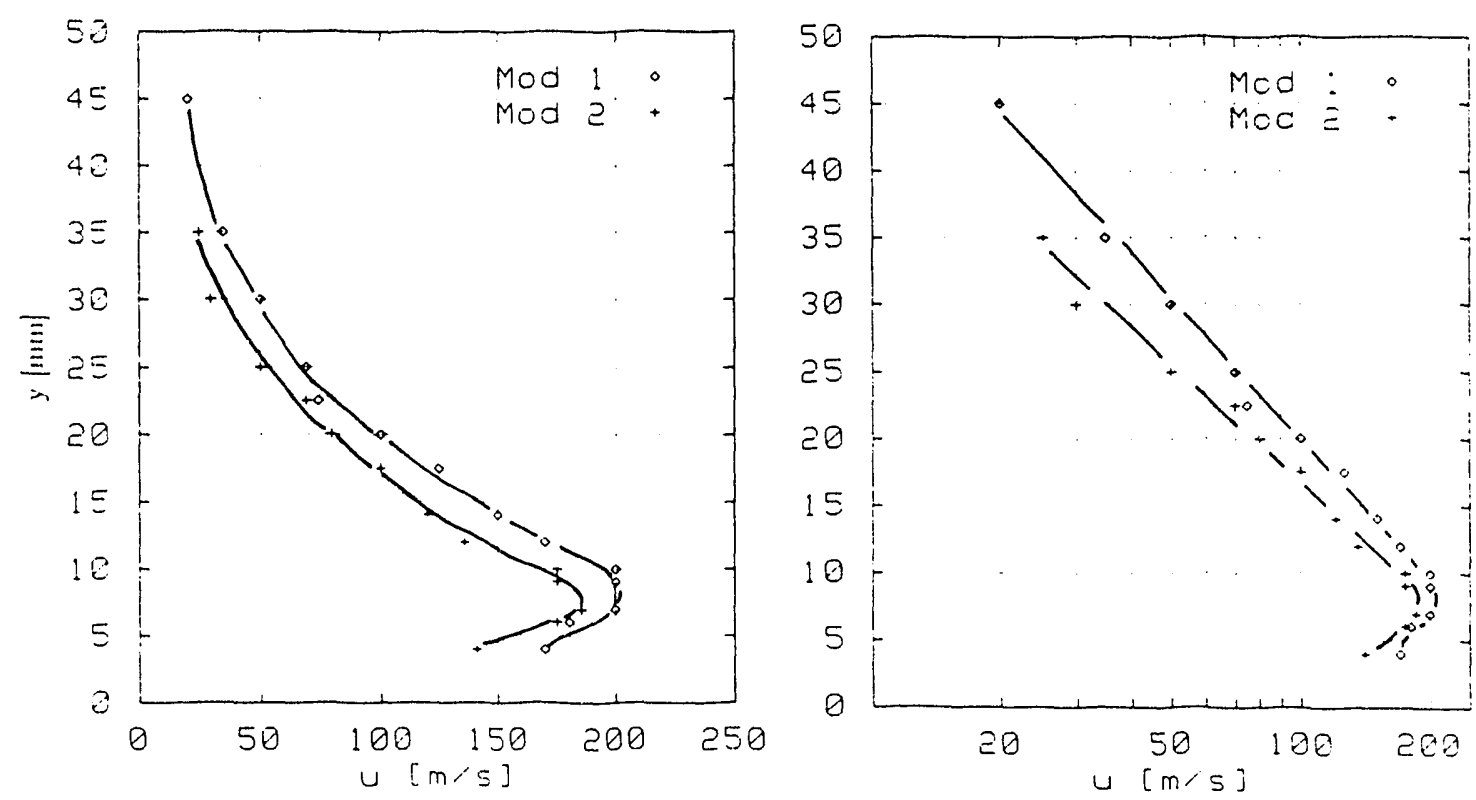

Figure i: Variation range of flow velocities 


\subsection{Instantaneous Velocity Profiles}

To give an overview of the flow dynamics of the whole layer a number of instantaneous flow profiles will be presented in the following. Figure 8 shows the 16 time instants at which such profiles were evaluated.

The Figures 9 to 11 show profiles in the regime of the periodic disturbance for the first four oscillations. Each plot consists of three curves: one for the profile at the instant of maximum velocity and one at the instant of the following velocity minimum. The third is for the instant dividing that interval into halves. For completeness these curves are plotted with linear, semilogarithmic and logarithmic axes.

The periodic disturbance jecays into a moderatively undisturbed shear flow. Figures 12 to 14 show the profiles for the times $1250,1500,1750$ and $2000 \mu \mathrm{sec}$.

To give a better overview of their time development, the profile are summarized in Figures 15 and 16 in groups of three curves in each plot. The instances chosen are those of the "zero-rrossing" in the periodic regime and the four profiles of undisturbed shear flow.

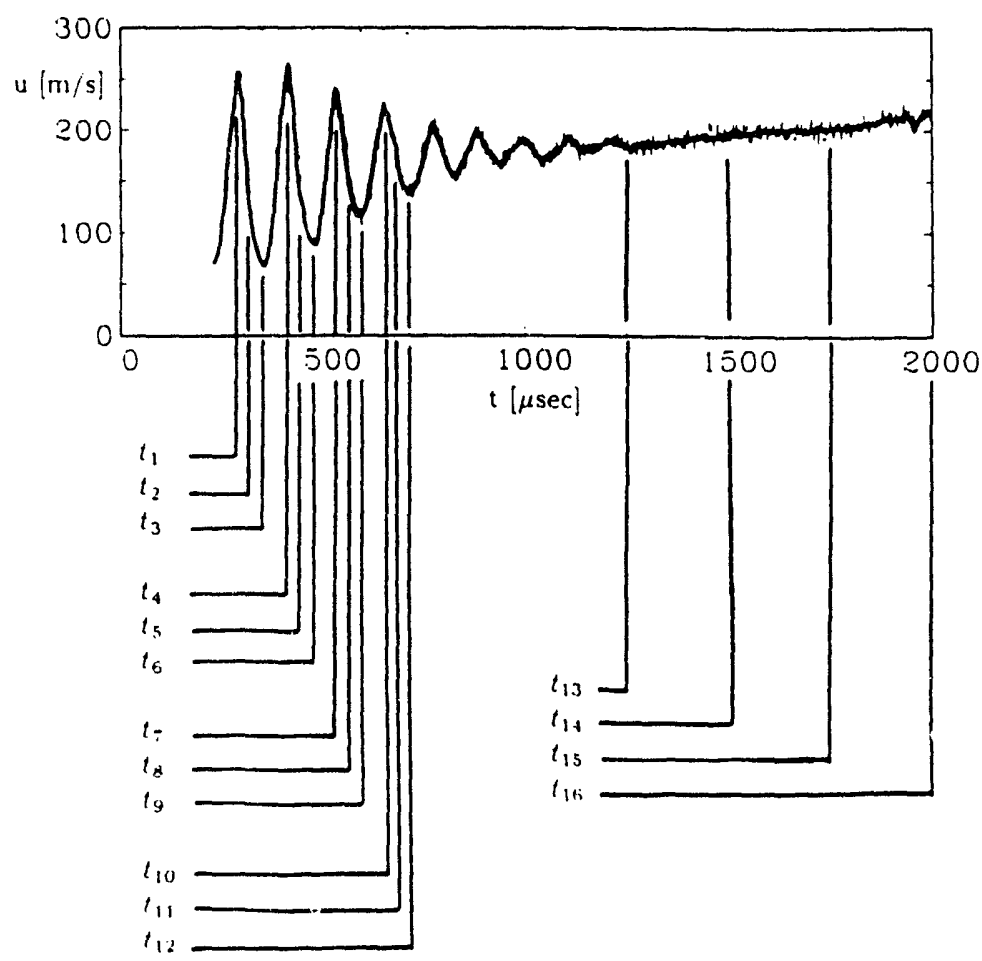

Figure s: showing the time instants for which flow profiles were evaluated 

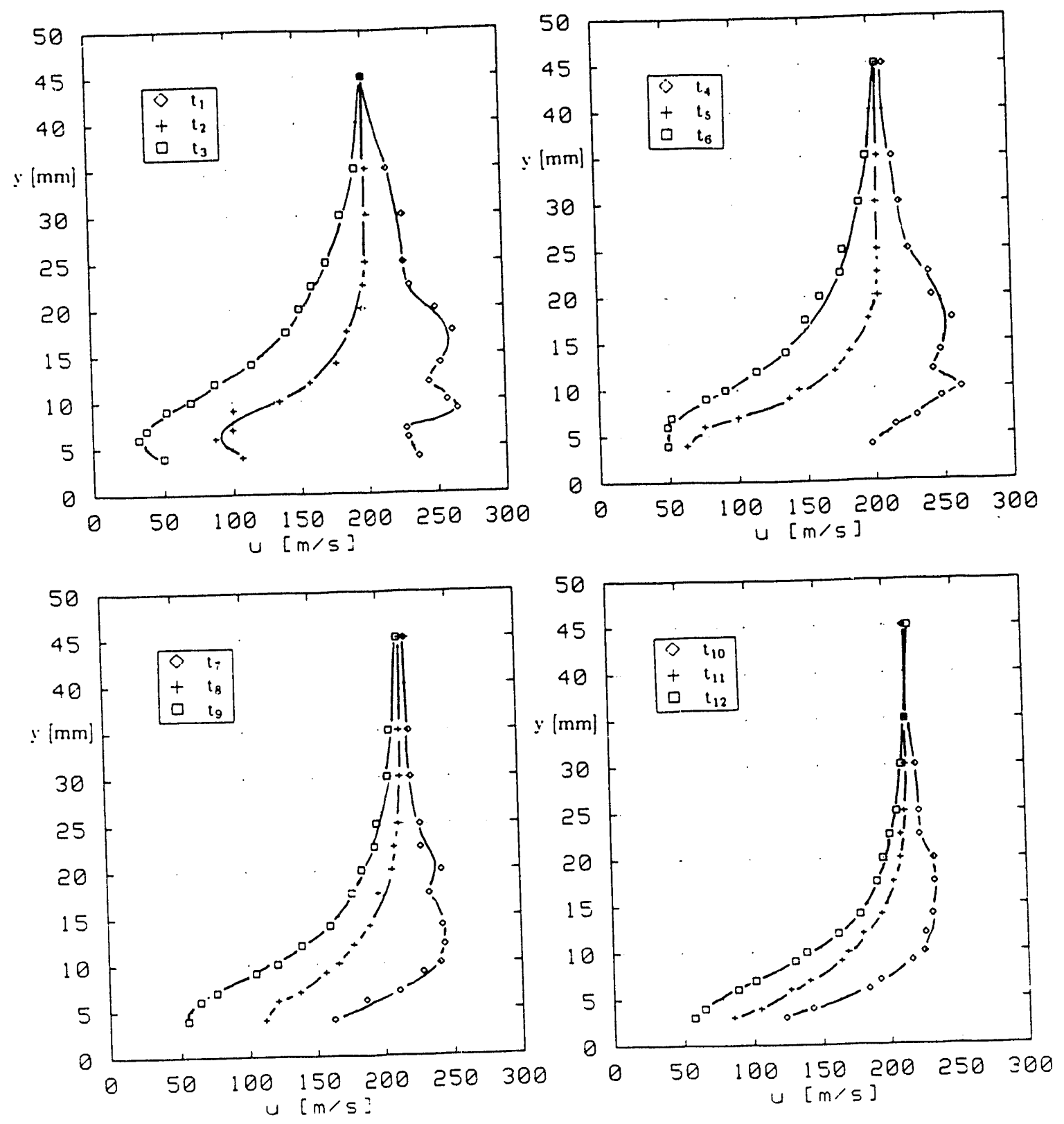

Figure 9: Instantaneous profiles of streamwise flow velocity

- Periodic regime -

(both scales linear) 

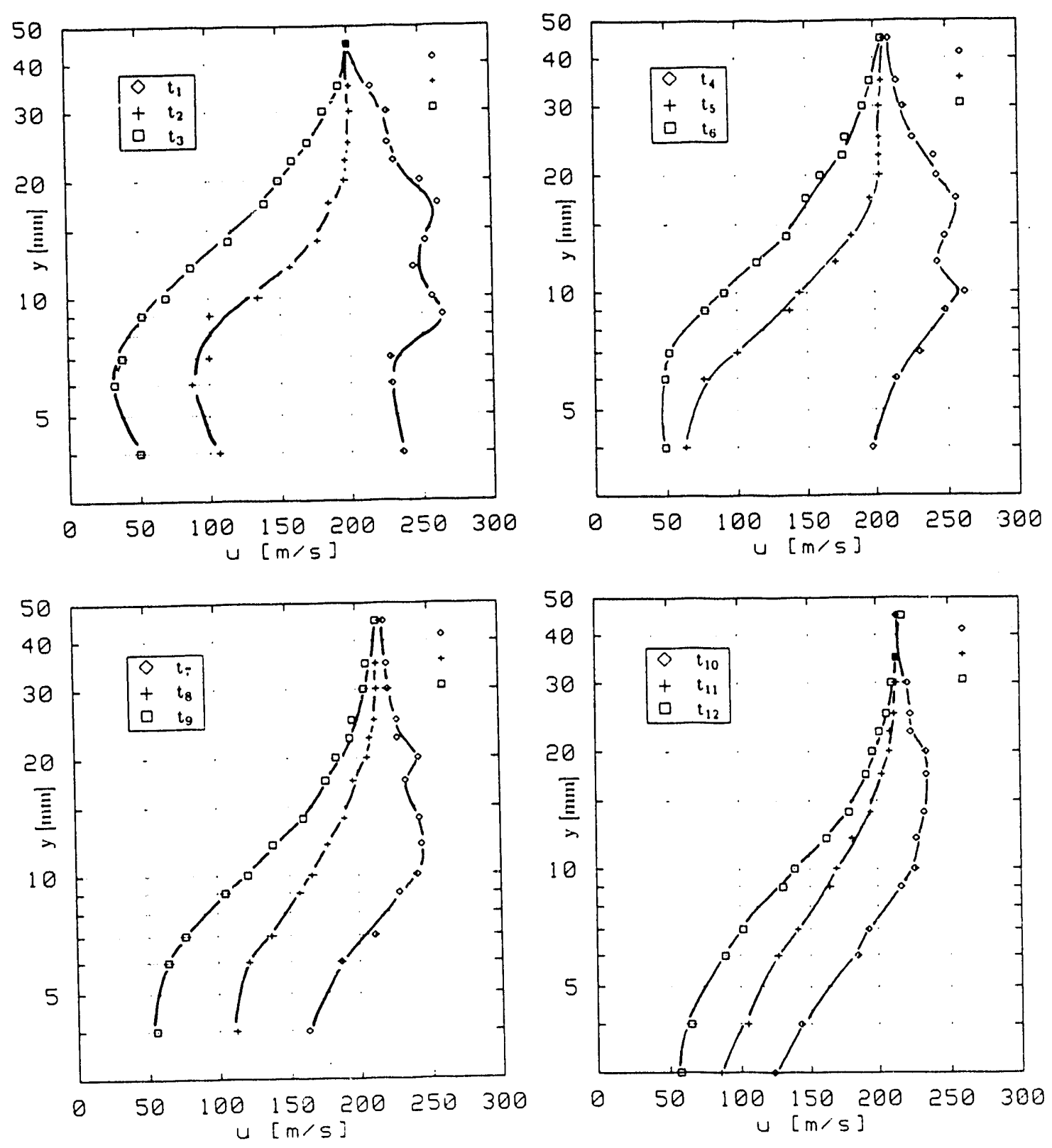

Figure 10: Instantaneous profiles of streamwise flow velocity - Periodic regime (y-scale logarithmic) 

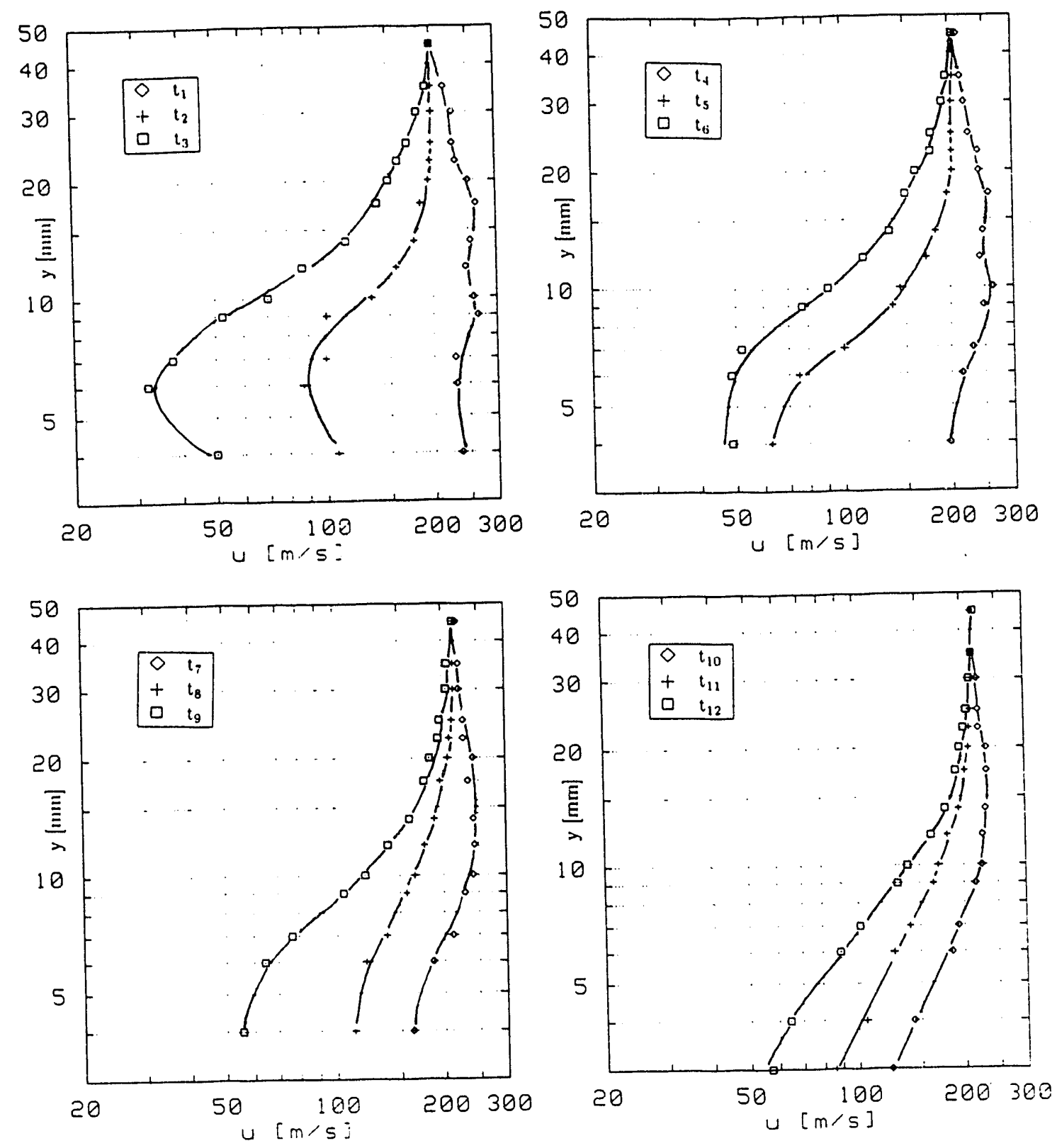

Figure 11: Instantaneous profiles of streamwise flow velocity - Periodic regime -

(both scales logarithmic) 

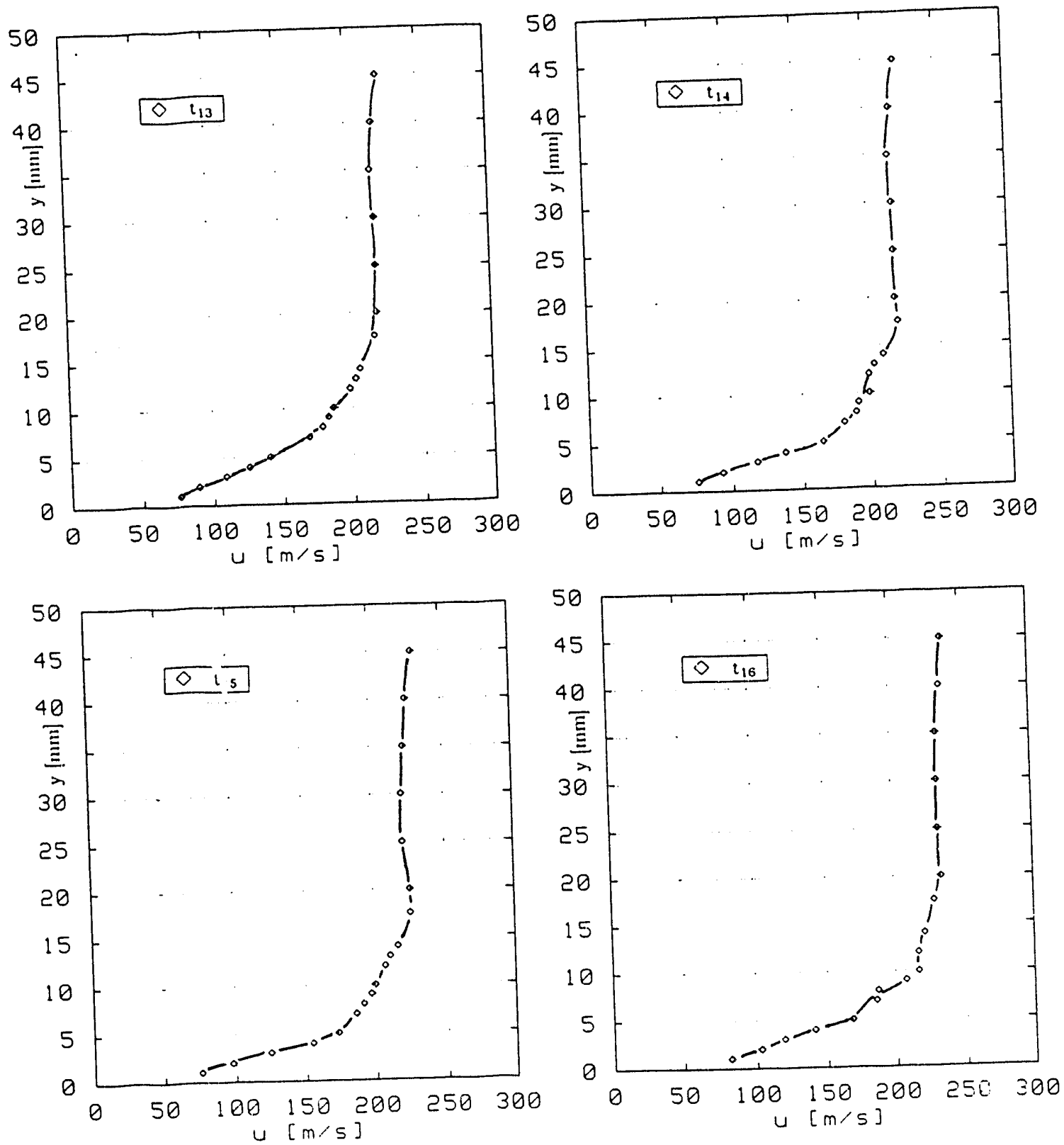

Figure 12: Instantaneous profiles of streamwise flow velocity

- Shear flow regime -

(both scales linear) 

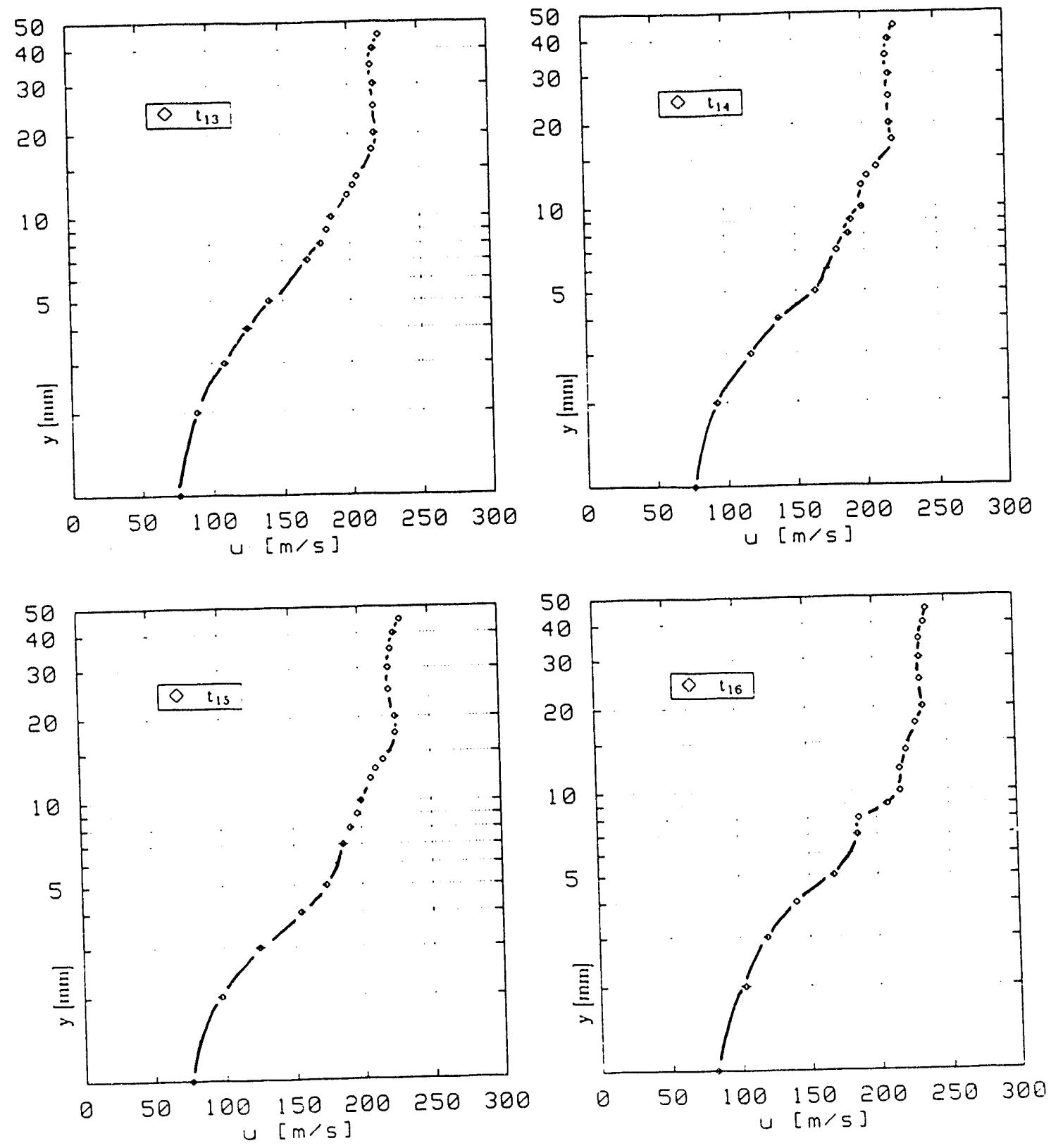

Figure 13: Instantaneous profiles of streamwise flow velocity

- Shear flow regime -

(y-scale logarithmic) 

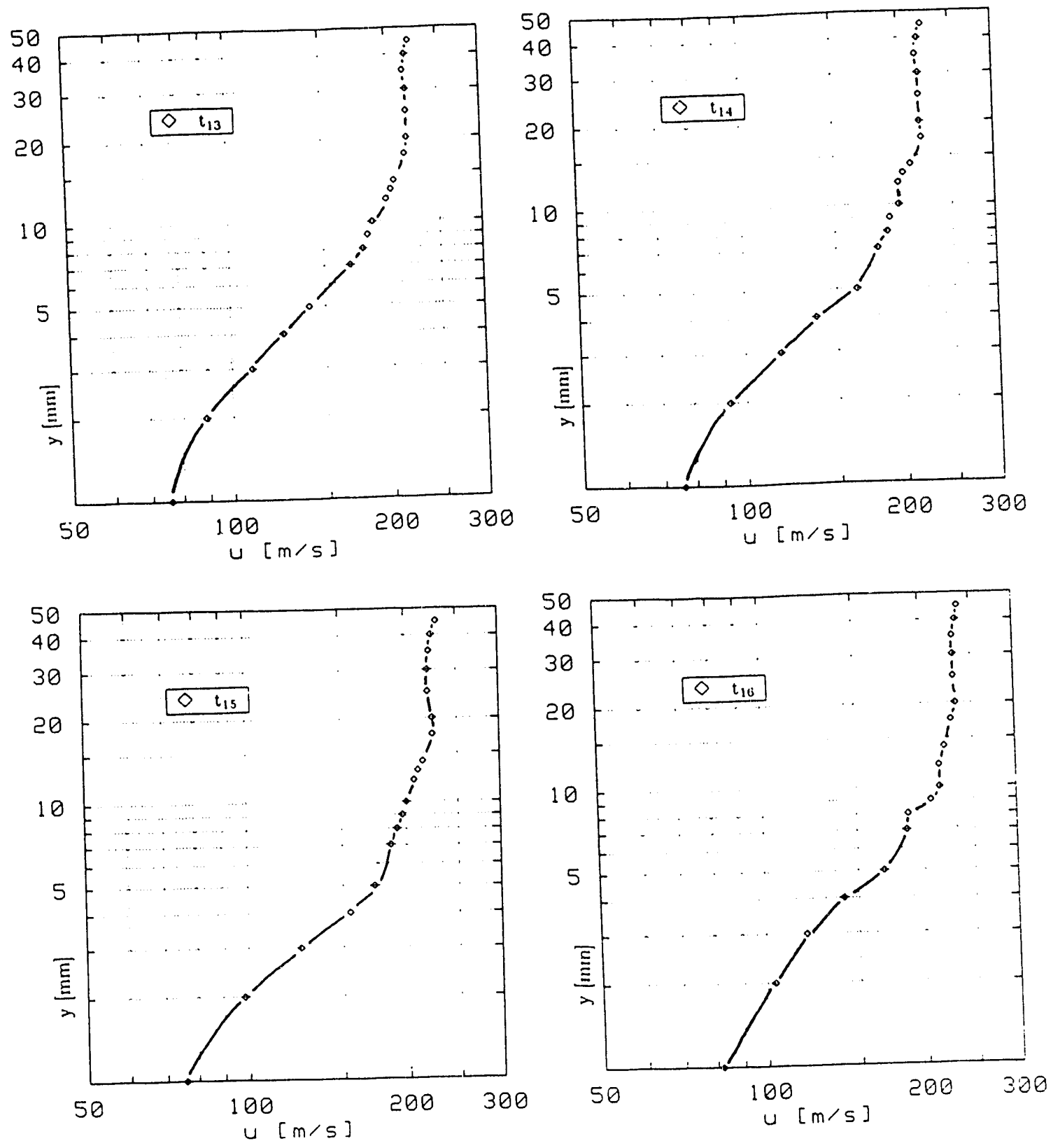

Figure 14: Instantaneous profiles of streamwise flow velocity

- Shear flow regime -

(both scales logarithmic) 

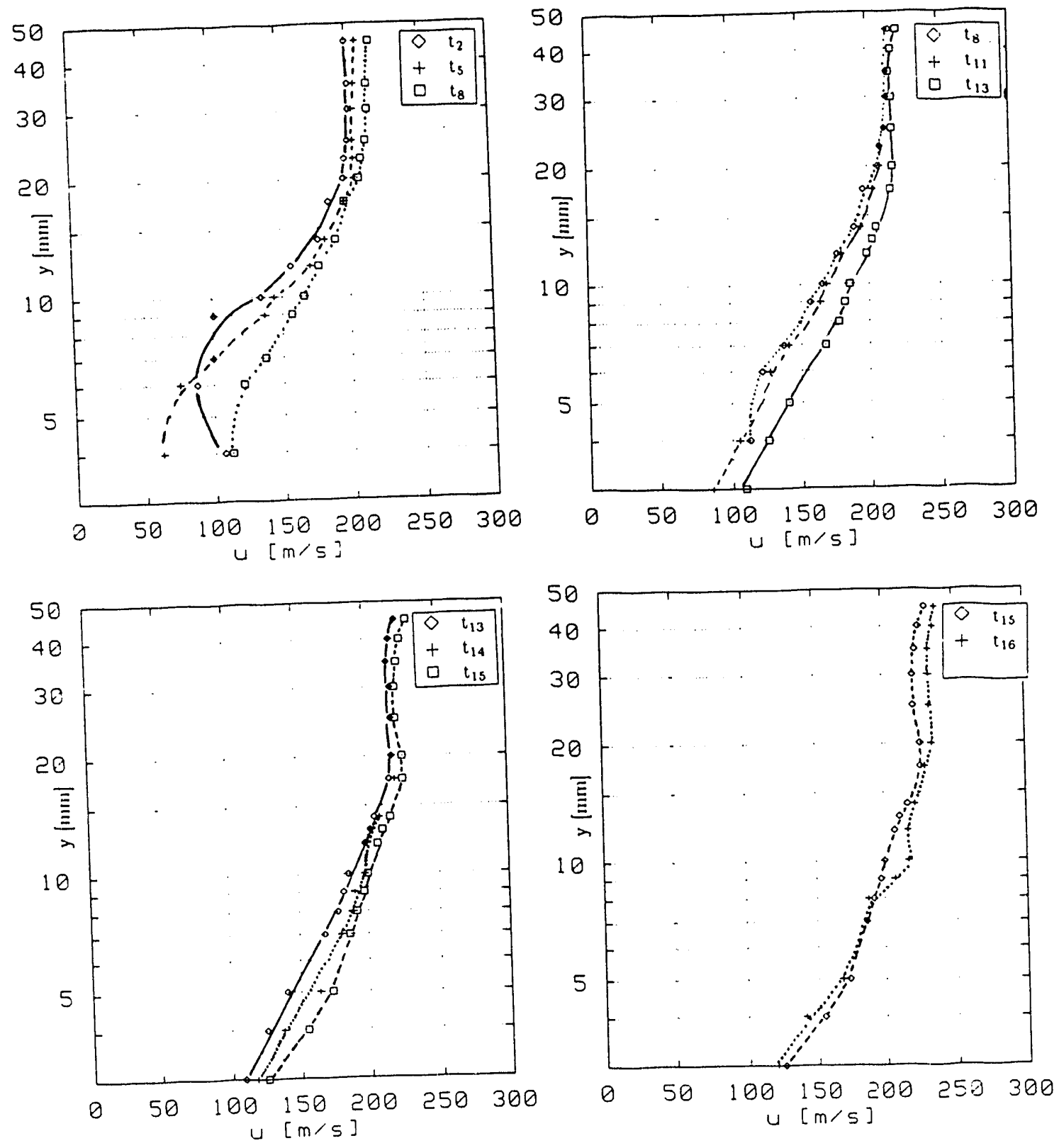

Figure 15: Time development of flow profiles (y-scale logarithmic) 

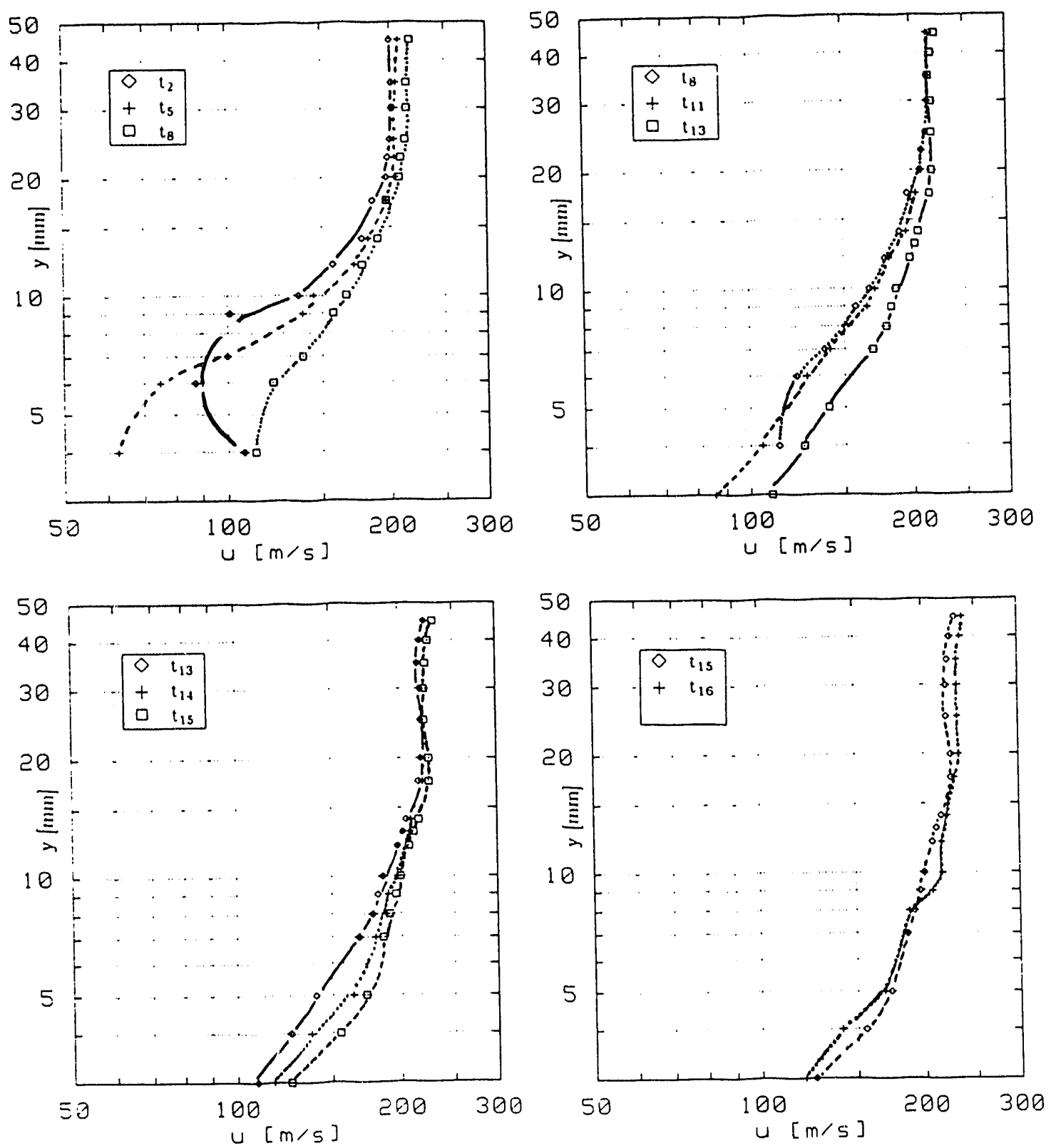

Figure 16: Time development of flow profiles (both scales logarithmic) 


\subsection{SCALING}

Up to now the data were presented in an unscaled version. In the shear flow regime, it is useful to scale the experimental data - in order to facilitate comparisons with other boundary layer flows. Specifically we have plotted the boundary layer profiles:

$$
\frac{\bar{u}}{U_{0}}=f(\eta)
$$

$$
\begin{aligned}
\eta & =y / \delta \\
\text { where } \delta & =98 \% \text { thickness } \\
U_{0} & =\text { free stream velocity }(\simeq 230 \mathrm{~m} / \mathrm{s})
\end{aligned}
$$

The results are presented in Figure 17. If one approximates the profile by a power law function

$$
\frac{\bar{u}}{U_{0}}=\eta^{a}
$$

one finds that the exponent varies between:

$$
0.26 \leq a \leq 0.38
$$

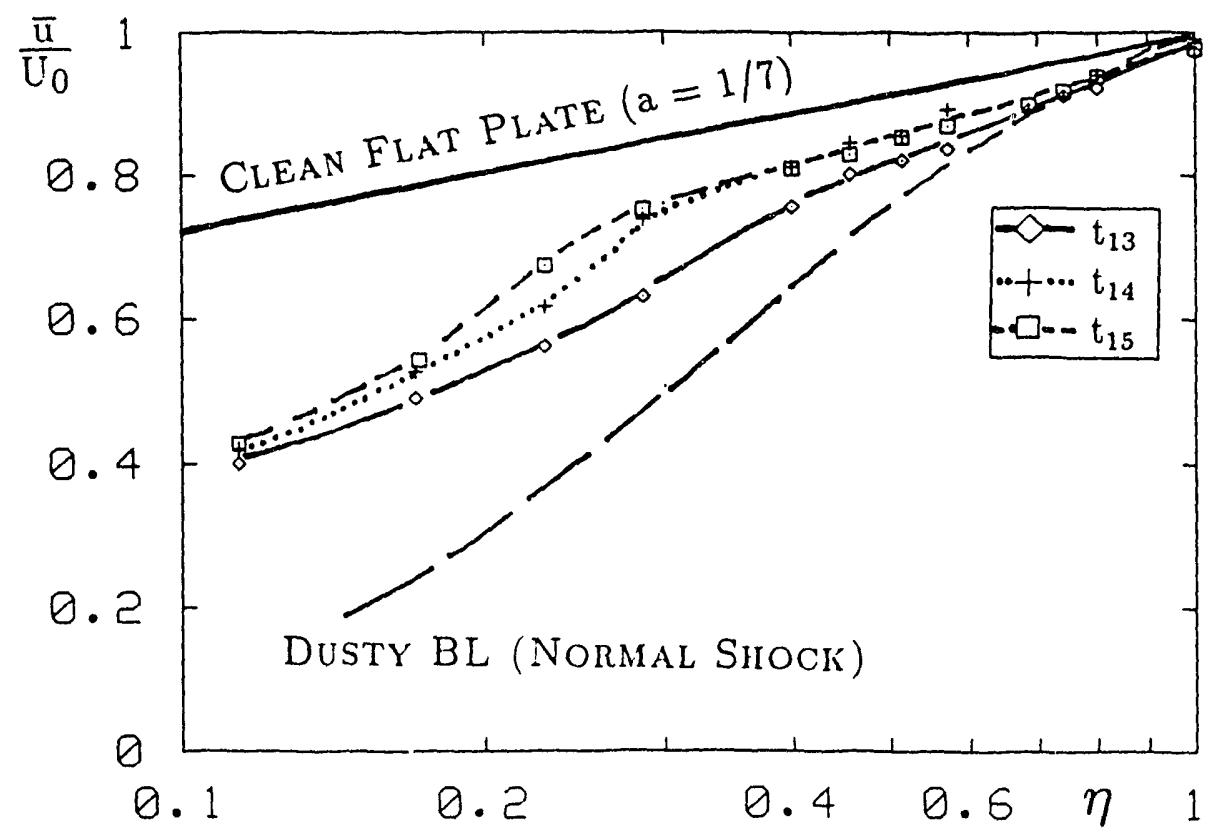

Figure 17: Scaled streamwise velocity profiles 


\section{SECTION 3 CONCLUSIONS}

Although the flow field displayed rather pronounced dynam:cs, reliable and reproducable velocity measurements could be made with the dual-beam Laser-DopplerVelocimeter. These results should be useful in validation of numerical simulations. The present results suggest further studies of the post-shock flow field with modified parameters like e.g. layer thickness or density ratio of the mixed gases. Nevertheless one has to keep in mind a number of experimental difficulties that might limit the application of the LDV system (e.g. limitations on the dynamic range of measurable flow velocities imposed by the choice of sampling and filtering frequencies and the resolution of the data processing) as well as problems that arise with homogenous particle seeding of the injected gases.

\section{LIST OF REFERENCES}

1. Kuhl, A. L., Reichenbach, H., and Ferguson, R. E.. (1991) Shock interactions with a dense-gas wall layer, Proceedings of the Eighteenth Int. Symposium on Shock Waves and Shock Tubes, Sendai University, 21 - 26 July 1991, Sendai, Japan (ed. K. Takayama), in press.

2. H. Reichenbach, P. Neuwald, A. Kuhl, Dense Gas Boundary Layer Experiments - Visualization, Pressure Measurements, Concentration Evaluation, Ernst-Mach-Institut, T 10/92 (November 1992)

3. P. Neuwald, H. Reichenbach et. al., Preliminary Measurements Applying the LDV System at the EMI Shock Tube, Ernst-Mach-Institut, T 6/92 (August 1992).

4. Batt, R. G., Kulkarny: $\because$ A., Behrens, H. W., and Rungaldier, H., Shockinduced boundary dust lofting, Shock Tubes and Waves, edited by $\mathrm{H}$. Grönig, VCH, We:nheim. Germany, 1988, pp. 209 - 215. 

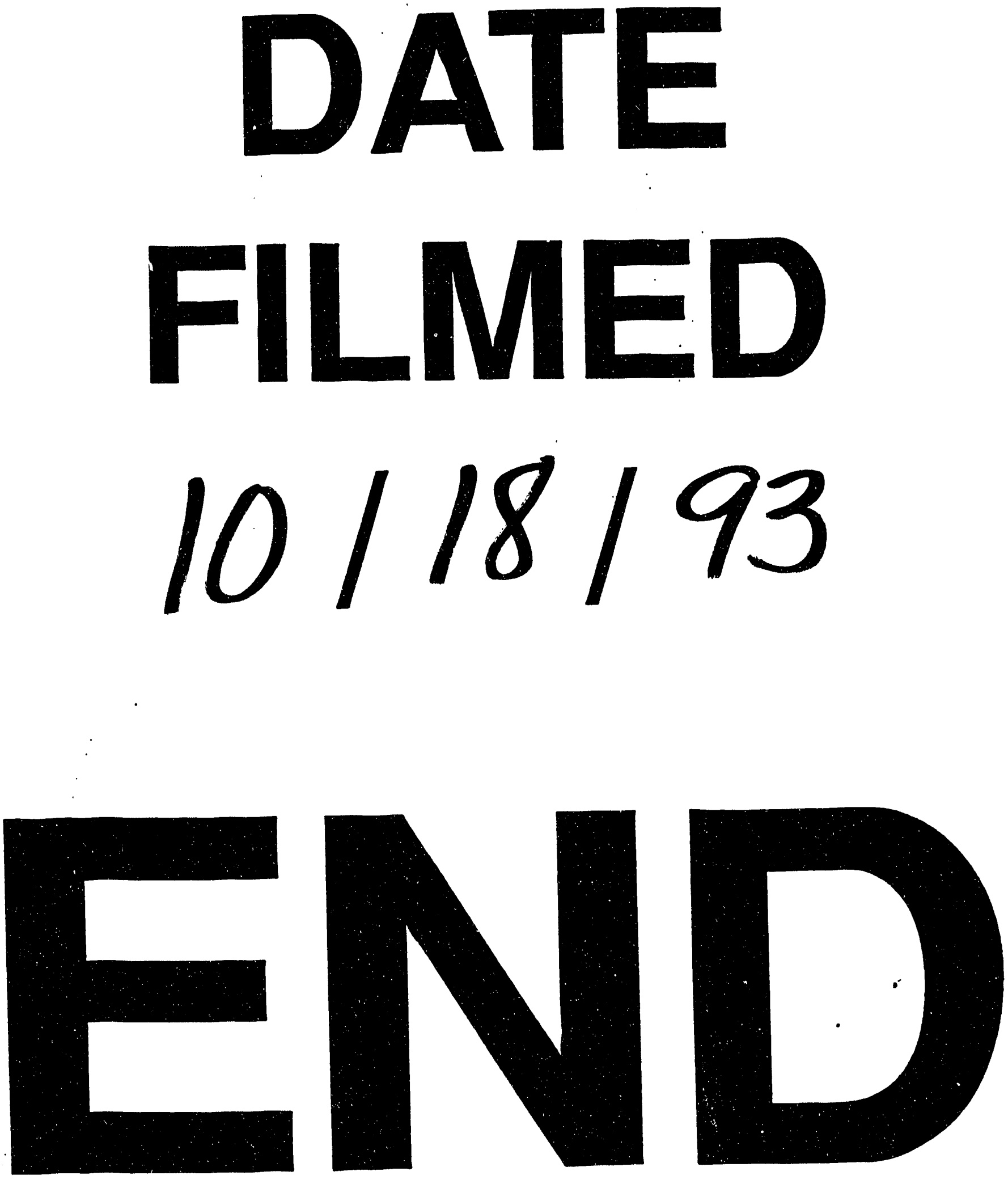
